\title{
A interiorização dos campi das Instituições Federais de Ensino Superior (IFES) e seus impactos no espaço urbano: um estudo de caso a partir da cidade de Viçosa-MG
}

\author{
The interiorization of federal Institutions of Higher Education campuses and its \\ impacts on urban space: a case study from the city of Viçosa-MG
}

Karine de Almeida Paula[a,b] (D), Teresa Cristina de Almeida Faria[c,d] (D)

\author{
[a] Universidade Federal de Viçosa (UFV), Viçosa, MG, Brasil \\ [b] Centro Universitario de Viçosa, Faculdade de Ciências e Tecnologia de Viçosa (FAVIÇOSA), Viçosa, MG, Brasil \\ [c] Universidade Federal do Rio de Janeiro (UFRJ), Rio de Janeiro, RJ, Brasil \\ [d] Universidade Federal de Viçosa (UFV), Departamento de Arquitetura e Urbanismo, Viçosa, MG, Brasil
}

Como citar: Paula, K. A., \& Faria, T. C. A. (2020). Instituições Federais de Ensino Superior (IFES) e seus impactos no espaço urbano: um estudo de caso a partir da cidade de Viçosa-MG. urbe. Revista Brasileira de Gestão Urbana, 12, e20190089. https://doi.org/10.1590/2175-3369.012.e20190089

\section{Resumo}

Este artigo tem como objetivo discutir os impactos e a influência no processo de produção do espaço urbano dos municípios que abrigam as Instituições Federais de Ensino Superior (IFES), tomando, como Estudo de Caso, o município de Viçosa-MG, onde se localiza a Universidade Federal de Viçosa (UFV). O estudo tem como foco analisar as transformações engendradas na zona central de Viçosa-MG, no tocante ao uso e ocupação do solo, a partir da instalação e ampliação das atividades da UFV, e o reflexo da presença da instituição na atuação dos promotores imobiliários locais. Para esta análise, foram utilizados, como fonte de dados, os alvarás e habite-se de construções, obtidos junto ao Instituto de Planejamento Municipal (IPLAM), autarquia da Prefeitura Municipal de Viçosa-MG, assim como o levantamento de dados e informações nas imobiliárias e corretoras da cidade. A partir das análises e observações, é possível mensurar que a UFV se mostra como um elemento norteador no processo de produção do espaço urbano por parte dos promotores imobiliários, assim como no processo de transformação dos usos do solo. Dessa maneira, foi possível notar uma relação entre o processo de urbanização, a atuação dos promotores imobiliários e os planos de expansão da UFV.

Palavras-chave: Instituições de Ensino Superior (IFES). Uso e ocupação dos espaços. Promotores imobiliários. Viçosa-MG.

\begin{abstract}
This article aims to discuss the impacts and influence on the urban space production process of municipalities that host the Institutions of Higher Education (IFES), considering the municipality of Viçosa-MG as a case study, where the Federal University of Viçosa (Universidade Federal de Viçosa - UFV) is situated. The study seeks to analyze the transformations engendered in the center of Viçosa - MG, regarding land use and occupation, including the installation and expansion of activities of the UFV, and reflection of the presence of the institution regarding the activities of local real estate developers. For this
\end{abstract}

KAP é geógrafa, mestre em Arquitetura e Urbanismo, professora, e-mail: karinealmeida.ufv@gmail.com

TCAF é arquiteta e urbanista, doutora em Planejamento Urbano e Regional, professora, e-mail: tcfaria.au@gmail.com 
analysis housing and construction permits were used as source data, obtained from the Municipal Planning Institute (Instituto de Planejamento Municipal - IPLAM), a division of the City Hall of Viçosa/MG, as well as collection of data and information from real estate agents and brokers in the city. From the analysis and observations, it is possible to determine that the UFV is a guiding element in the process of urban space production by real estate developers, as well as in the process of land use transformation. Therefore, it was possible to note a relationship between the urbanization process, the actions of real estate developers and the UFV expansion plans.

Keywords: Institutions of Higher Education (IFES). Use and occupancy of spaces. Real estate developers. Viçosa-MG.

\section{Introdução}

Este artigo tem como tema a influência e o impacto de Instituições Federais de Ensino Superior - IFES no processo de urbanização e produção do espaço urbano de cidades pequenas e médias. Para tanto, será analisado um estudo de caso referente à cidade de Viçosa-MG, onde está localizada a Universidade Federal de Viçosa - UFV1.

Dessa forma, este artigo traz como objetivo, especificadamente, discutir o impacto e a influência da Universidade Federal de Viçosa sobre a atividade imobiliária na zona central da cidade, refletindo diretamente sobre a produção do espaço urbano e no papel e atuação dos promotores imobiliários locais.

É notório, principalmente nas duas últimas décadas, que as IFES têm se tornado objeto de programas governamentais com o intuito de reestruturá-las internamente e expandi-las. De forma contextual, em 2007, foi criado pelo Governo Federal o Programa de Apoio a Planos de Reestruturação e Expansão das Universidades Federais - Programa REUNI) através do Decreto 6.096, de 24 de abril, impulsionando a criação de novos cursos de graduação e de pós-graduação. Ocorrem, então, a contratação de novos servidores, a criação de novas vagas, além da construção e reforma de edifícios. O REUNI foi implantado em todas as Universidades Federais do país, resultando em mudanças na reestruturação interna e também na expansão de cursos e vagas na própria sede da Universidade e nos novos campi criados em outras cidades. Além do mais, o Programa assegurou a criação de novas universidades, sobretudo em cidades pequenas e médias, localizadas no interior do país, tendo como objetivo maior a descentralização da oferta de vagas, concentradas geralmente nas grandes cidades (Paula, 2019).

Especificadamente, em Minas Gerais, existiam 21 campi até a implantação do REUNI. Com a implantação do Programa, foram criados 16 novos campi. Em nível de Brasil, a interiorização de novos campi proporcionou uma expansão relativa, elevando-se o número de municípios atendidos por universidades federais, de 114 para 272 entre 2003 e 2010. Já entre 2011 e 2014, houve a criação de 47 novos campi pelo país (Weska et al., 2012). Muitos desses municípios são de pequeno e médio porte demográfico.

Referente à cidade de Viçosa-MG, com população em torno de $78.286^{2}$ habitantes, a fundação da Universidade Federal de Viçosa (UFV) ocorreu em 1926, inicialmente como a Escola Superior de Agricultura e Veterinária (ESAV), passando em 1948 a se transformar na Universidade Rural do Estado de Minas Gerais (UREMG) e, em 1969, ser federalizada. A partir da década de 1980, e, de forma mais intensa, a partir dos anos 2000, observa-se o impacto da UFV na produção do espaço urbano, com a intensificação da atividade imobiliária, principalmente na zona central, marcada por uma produção significativa de imóveis, com destaque para a verticalização, o alto valor dos imóveis (tanto para locação quanto para venda) e a alta especulação imobiliária (os terrenos da zona central têm auferido valores bem elevados para uma cidade interiorana).

\footnotetext{
${ }^{1}$ Para fins de enquadramento, a Universidade Federal de Viçosa (UFV) foi categorizada, neste trabalho, como uma Instituição Federal de Ensino Superior (IFES).

${ }^{2}$ Soma-se a população nativa cerca de 16.000 habitantes constituídos pelos estudantes, pois os mesmos não são contabilizados pelo IBGE como população local, sendo caracterizados como uma "população flutuante".
} 
No que diz respeito à estrutura física e administrativa da Universidade, esta possui três campi, um na cidade de Florestal, um em Rio Paranaíba e um em Viçosa, todos eles localizados no estado de Minas Gerais. Atualmente, o campus da UFV em Viçosa conta com 45 cursos de graduação, 23 programas de pós-graduação (mestrado e doutorado) e um Colégio de Aplicação - COLUNI, que oferece, anualmente, 150 vagas. A UFV possui em torno de 16.000 estudantes, sendo a grande maioria originária de outras cidades. Tal população não é contabilizada pelo IBGE, se caracterizando como uma "população flutuante".

Outra cidade que abarca um campus da UFV é Florestal - com 6.603 habitantes -, localizada na Região Metropolitana de Belo Horizonte e distante 276,4 km de Viçosa. Este novo campus possui seis cursos técnicos e 10 cursos de graduação, que juntos somam 1.500 estudantes. Os estudantes equivalem a quase $22 \%$ da população total do município, um percentual que demanda habitação e serviços. Dessa forma, é possível observar um processo de reestruturação na cidade, movimentado a dinâmica imobiliária local.

Já no que tange aos outros campi mais recentes, a partir de 2006, a UFV passa a expandi-los para cidades interioranas de Minas Gerais e a escolhida foi Rio Paranaíba - cidade mineira com população de 11.885 habitantes, distante 531,4 km de Viçosa. 0 campus, na época, ofertava dois cursos de graduação: Agronomia e Administração. Com o REUNI, passou a oferecer 10 cursos de graduação. Atualmente, são 1.481 estudantes, 87 docentes efetivos e 54 técnicos administrativos.

Num contexto mais amplo, as análises dos planos de expansão das IFES não evidenciam as contrapartidas por parte do Governo Federal aos municípios, na tentativa de equacionar ou amenizar os impactos retroativos que podem causar no processo de produção do espaço urbano. Haja vista que a criação de novos cursos e, consequentemente, o aumento das vagas, assim como as contratações de servidores, podem favorecer a geração de novas demandas, sejam elas habitacionais, de serviços, insfraestruturais, etc. Frente aos novos processos colocados, o mercado imobiliário, por sua vez, passa a observar as demandas como um potencial para o seu aquecimento, inflacionando os preços dos imóveis, materializando e/ou potencializando um cenário marcado pela especulação imobiliária (Paula, 2019).

No crescimento do número de IFES em cidades fora do âmbito das regiões metropolitanas e de cidades acima de 100 mil habitantes, evidencia-se um fenômeno de interiorização dessas instituições, revelando, nos dizeres de Amorim (2010), uma genuína conquista do território. Dessa maneira, advoga-se que as cidades pequenas e médias - como é o caso de Viçosa, Rio Paranaíba e Florestal - estão vivenciando significativas transformações socioespaciais decorrentes da criação ou expansão das IFES presentes em seu território, sem qualquer apoio do governo federal ou estadual.

As análises referentes às transformações engendradas nestas cidades são de muita valia, à medida que possibilitam compreender a dinâmica de funcionalidade dos espaços e os interesses envolvidos no mesmo. De acordo com Magalhães (2014), o campus universitário pode ser considerado um equipamento singular, capaz de moldar o seu entorno, podendo afetar a vida daqueles que vivem nas proximidades e exercer um considerável impacto sobre o meio onde se insere.

Neste sentido, acredita-se que o tema seja muito pertinente a partir do momento em que se deseja compreender, um pouco mais, a respeito das dinâmicas imobiliárias instaladas aos espaços, assim como as formas como tem sido concebido o espaço urbano e os conflitos que têm sido engendrados no mesmo a partir das disputas pelos espaços em consequência da influência e presença das IFES.

É notória a existência de alguns trabalhos que abordam a funcionalidade e a existência de campi universitários em várias cidades brasileiras, mas trabalhos que explorem, de forma mais conceitual e ilustrativa, o impacto da presença das IFES nas cidades e as transformações engendradas no espaço urbano são relativamente escassos, principalmente em cidades interioranas, de pequeno a médio porte. Localidades estas que mais têm recebido campi nos últimos anos, cerca de 47 entre 2011 e 2014, conforme atesta Weska et al. (2012).

Os estudos que relacionam a cidade e as IFES geralmente tendem a abordar as reestruturações dos campi universitários, ou seja, restringem as análises ao ambiente interno das instituições. Em alguns casos, abordam a cidade, mas não há uma atenção mais precisa quanto ao impacto que estas instituições trazem para a estruturação do espaço urbano. Corrobora com esta ideia Sayegh (2009), ao destacar a não existência de trabalhos que procurem entender a dinâmica urbana de uma cidade que abriga um campus 
universitário no Brasil, mesmo diante de um número relativo de cidades dinamizadas pela sua função universitária.

Neste contexto, o trabalho, na tentativa de elucidar melhor a discussão, foi estruturado em quatro seções. Primeiramente, esta introdução, que aborda o objetivo do trabalho e o problema; a segunda, que discutirá as transformações urbanas engendradas pela instalação de IFES, assim como as características das cidades universitárias; a terceira seção analisa a presença da UFV na cidade, como um importante fixo que tende a nortear e influenciar as decisões e ações dos promotores imobiliários locais, assim como as transformações nos usos do solo. E, por fim, na quarta seção, são apresentadas as considerações finais do trabalho.

\section{Transformações urbanas a partir da implementação das IFES}

A produção das cidades passou a ser vista como um grande negócio para determinados grupos. 0 espaço, cada vez mais, se coloca como um espaço mercadoria, em que o capital prevalece e passa a ditar regras, como afirma Sánchez (2010). Vários são os agentes que participam no processo de estruturação das cidades, adotando estratégias que variam no tempo e espaço, e esta variabilidade deriva tanto de causas externas como de causas internas, vinculadas às condições intrínsecas ao tipo de capital de cada agente $^{3}$ (Correa, 2000, 2011).

Tais agentes mencionados por Correa (2011, p. 43) são responsáveis pela produção do espaço e se configuram como

[...] agentes sociais concretos, históricos, dotados de interesses, estratégias e práticas espaciais próprias, portadores de contradições e geradores de conflitos entre eles mesmos e com outros segmentos da sociedade.

Dentro desta ótica, está a organização dos espaços voltados a suprir as demandas colocadas a partir da instalação e/ou expansão de instituições federais de ensino. Afinal, as tais instituições, ao se inserirem na dinamização urbana, acabam por gerar uma nova centralidade ou contribuir para a recuperação e mudança de uso do espaço urbano, seja do seu campus quanto dos seus arredores (Sanfeliu, 2011).

De acordo com Baumgartner (2015b), desde a segunda metade dos anos 2000, é possível observar uma significativa expansão das instituições (Universidades e Institutos Tecnológicos) federais de ensino superior (IFES) de vários estados brasileiros em direção às cidades médias e pequenas do interior. De acordo com Pinheiro (2018, p. 41), "[...] as universidades têm sido implantadas como estratégia de desenvolvimento e modernização local e regional, em especial nas cidades pequenas".

É notável que, nos últimos anos, em nível de Brasil, o número de IFES tenha apresentado um aumento consubstancial, principalmente no Governo Lula, e muitas destas instituições acabaram por instalar seus campi em cidades pequenas e médias, configurando uma rede interiorana de ensino superior e tecnológico.

Neste âmbito, ao se relacionar a presença de IFES em diversas cidades interioranas, é comum associar-se ao conceito de cidade universitária. Tal expressão, cidade universitária, é mencionada por Sayegh (2009), mas extrapola a noção de campi universitários, denotando um sentido diferente, que se refere, principalmente, às cidades pequenas ou médias, que passaram a ter seu espaço urbano fortemente dinamizado mediante a inserção de uma ou mais instituições de ensino superior.

À vista disso, é relevante considerar que o conceito de cidade universitária tem sido discutido por diversos autores, dentre eles, Sanfeliu (2011), que apresenta uma síntese da evolução deste conceito a partir da perspectiva histórica, considerando o caso da Universidad de Lleida, na Espanha, destacando o

\footnotetext{
${ }^{3}$ Correa $(2000,2011)$ elenca cinco tipos de agentes sociais responsáveis pela produção do espaço urbano, sendo eles: os proprietários dos meios de produção, os proprietários fundiários, os promotores imobiliários, o Estado e os grupos sociais excluídos. No processo de produção da cidade, cada um desses agentes é dotado de interesses específicos, sendo alguns contraditórios e outros comuns. Sem desmerecer o importante papel desempenhado por todos os agentes na produção da cidade, esse trabalho dará especial ênfase à atuação dos promotores imobiliários.
} 
papel das universidades no desenvolvimento urbano das cidades que as abrigam. A autora apresenta três tipologias básicas de implantação das universidades dentro das cidades: o campus periférico (campus isolado), o campus urbano concentrado e o campus urbano disperso.

Referente ao modelo campus periférico, este tem relação direta com o modelo de localização periférica, afastado e separado do tecido urbano estabelecido, sendo um modelo implantado, inicialmente, nos Estados Unidos, desde o final do século XVIII. Já na Europa, diferentemente da situação anterior, o modelo de campus isolado se coloca como um tipo de atividade recente, sendo incentivado mediante o crescimento do número de universitários dos anos 1960, a massificação de alguns centros universitários e a criação de novas universidades, tendo sido uma exceção, a criação da Cidade Universitária de Madri, em 1927. Neste tipo de campus, o mesmo não mantém uma relação direta com a estrutura urbana, salvo apenas em casos nos quais as áreas produtivas necessitam do conhecimento universitário ou mão de obra qualificada, como é o caso de alguns parques tecnológicos, em que a universidade acaba por gerar um papel salutar na localização de concentrações de empresas de alta tecnologia (Sanfeliu, 2011).

Diferentemente do campus isolado, tem-se, a partir da tradição histórica europeia, a inserção física da universidade dentro da cidade, levando a criação de cidades universitárias reais, nos dizeres de Sanfeliu (2011). 0 campus concentrado é marcado pela localização de instalações universitárias em uma área específica da cidade, chegando a desempenhar um papel similar ao dos campi periféricos, porém incorporado ao tecido urbano. Mesmo se apresentando bem semelhante ao modelo anterior, possui melhor interação com o tecido urbano, devido à proximidade. Observa-se que, de forma frequente, esses campi foram, inicialmente, construídos nos arredores da cidade e foram sendo incorporados a partir do crescimento ou expansão urbana. A Universidade de Complutense de Madri, na Moncloa, é um exemplo dessa tipologia (Sanfeliu, 2011).

E, por fim, é apresentada por Sanfeliu (2011) a tipologia de campus urbano disperso, que resulta na dispersão de equipamentos e instalações no tecido urbano. Neste caso, não é observado uma concentração massiva de equipamentos universitários, pois as instalações e a vida universitária se diluem no tecido urbano, e em muitos casos, com sede no núcleo histórico, contribuindo, assim, para a formação de novas centralidades.

Neste contexto, ao analisar as alterações espaciais promovidas pela instalação de IFES, acredita-se, nos dizeres de Pinheiro (2018), que este equipamento universitário é capaz de promover transformações salutares no que se refere a organização e dinâmica do espaço urbano, tanto na construção quanto na valorização imobiliária, atraindo novas formas de comércio, impulsionando atividades no setor terciário, ressignificando espaços públicos e atraindo novos habitantes.

Segundo Baumgartner (2015a), as cidades recebem grandes investimentos e estes trazem consigo um aumento na migração de pessoas com alta qualificação profissional (professores universitários, pesquisadores, técnicos, administradores e outros), assim como de estudantes universitários, muitos deles com alto poder aquisitivo. Referente aos alunos de baixa renda - e que não são atendidos pelos programas de moradia estudantil -, eles também irão provocar um impacto no mercado imobiliário das cidades, mediante a necessidade de se prover moradias para atender à demanda. Desse modo, surgem as moradias coletivas, caracterizadas como repúblicas, que também fazem parte das estratégias dos investidores imobiliários.

Para Sayegh (2009), nas grandes metrópoles, nem sempre a implantação de uma cidade universitária é vista como um fator dinamizador, afinal há outros fatores que impulsionam diversas dinâmicas, tais como a implantação de indústrias, serviços e outras atividades. Mas, nas cidades, tanto nas médias quanto pequenas, as universidades e os campi acabam se materializando como grandes empregadores, se mostrando, em algumas delas, como as maiores fontes de emprego e detendo orçamentos superiores aos próprios municípios (Baumgartner, 2015a).

Neste sentido, como bem alega Pinheiro (2018, p. 41),

[...] as IES são capazes de movimentar, modelar e remodelar o espaço urbano e as dinâmicas sociais, uma vez que possuem potencial para promover impactos diretos e indiretos como geração de empregos; construção de edifícios impulsionando a construção civil; atração de profissionais 
qualificados; abertura e/ou melhoria de novos comércios (hotéis, pousadas, restaurantes, etc.); novos e melhores serviços (de saúde, educação, transporte, lazer, etc.).

À vista disso, nota-se que a instalação e/ou ampliação de uma instituição federal de ensino traz consigo demandas por novas unidades habitacionais, por exemplo, dada a migração de pessoas a cidades, dentre as quais professores, estudantes e servidores, como já mencionado. E esta demanda tende a acarretar um aumento dos valores dos aluguéis e dos imóveis, haja vista que o estoque habitacional nas cidades pequenas e médias, em muitos casos, se mostra pequeno. Dessa maneira, empresas de maior capitalização passam a construir novas moradias, sendo possível observar uma proliferação de imóveis em condomínios ou loteamentos (Baumgartner, 2015a).

De uma forma geral, vale destacar - e reiterar - o papel considerável das IFES nos espaços urbanos e o seu poder de ressignificação e de novas centralidades. Dentro da análise da ressignificação dos espaços e centralidades, vale destacar a atuação dos promotores imobiliários, colocados como agentes capazes de modificar e estruturar o espaço urbano. Em muitos casos, as IFES são colocadas como elementos de influência na reestruturação dos espaços, assim como elementos influenciadores da atividade imobiliária e, logo, da atuação dos promotores imobiliários. Agentes estes classificados por Correa (2000) como responsáveis pela realização, de forma parcial ou total, das funções de incorporação, financiamento, estudo técnico, construção ou produção física do imóvel, e de comercialização ou transformação do capital-mercadoria em capital-dinheiro (Correa, 2000).

\section{Transformações engendradas na zona central de Viçosa-MG sob a lógica mercadológica e o papel da UFV nesse processo}

As análises efetivadas se pautaram no recorte espacial colocado pela zona central, área adjacente ao campus e que concentra o maior número de equipamentos comerciais. Para a caracterização do perímetro da zona central, recorreu-se à delimitação proposta pela Lei de Uso e Ocupação da Cidade Lei $1.420 / 2000$.

Para substanciar as análises, foram obtidos dados junto ao Instituto de Planejamento Municipal (IPLAM), autarquia da Prefeitura Municipal de Viçosa-MG, referente ao número de habite-se emitidos, assim como por meio do levantamento de dados e informações nas imobiliárias e corretoras da cidade. Referente aos dados dos alvarás, foram obtidos e compilados os dados dos imóveis construídos na zona central, sobretudo imóveis verticalizados, nas décadas de 1980, 1990 e 2000, assim como dados de demolições, neste mesmo período. A partir do levantamento destes dados, foi possível realizar cruzamentos entre os momentos de aquecimento do mercado imobiliário e os programas de reestruturação e expansão da UFV.

No que se concerne aos dados obtidos por meio das imobiliárias e corretoras, estes se configuraram por meio de entrevistas semiestruturadas a uma amostra composta por seis corretores imobiliários atuantes em Viçosa, com a finalidade de coletar informações temporais que auxiliassem na compreensão do perfil, da atuação e das estratégias dos promotores imobiliários locais. Como critério para a seleção, optou-se por três corretores atuantes desde a década de 1980 e três corretores atuantes desde a década de 19904. Para a sistematização, assim como para a análise e interpretação das informações coletadas durante as entrevistas, recorreu-se à técnica de análise de conteúdo.

Estes dados foram cruciais para o levantamento do número de imóveis construídos na zona central, dentro de um recorte temporal de aproximadamente 30 anos, assim como importantes para se compreender o contexto que estava por detrás dos interesses imobiliários, respaldando as análises e as hipóteses levantadas. A espacialização e as análises dos dados (quantitativos e qualitativos)

\footnotetext{
4 Tendo em vista a dificuldade de se encontrarem os seis corretores que começaram a atuar no mercado desde a década de 1980 - e que ainda continuam atuando -, optou-se por selecionar 3 (três) corretores atuantes desde a década de 1980 e 3 (três) corretores atuantes desde a década de 1990.
} 
possibilitaram a intepretação da cidade, mais precisamente da zona central, como um locus da reprodução do capital, produzido a partir dos ditames da lógica imobiliária/mercadológica.

Dessa maneira, dentre os impactos resultantes da instalação das IFES na estruturação do espaço urbano, este artigo destaca, em particular para a zona central de Viçosa, as transformações nos usos do solo, as mudanças nas formas de morar, o crescimento do mercado imobiliário e a atuação proeminente dos promotores imobiliários e investidores. Neste sentido, este artigo visa ilustrar e analisar a possível influência da UFV no papel e na atuação dos promotores imobiliários em Viçosa-MG, assim como nas mudanças no uso e ocupação dos espaços na zona central ${ }^{5}$.

Inicialmente, o trabalho parte do pressuposto de que os planos de expansão da UFV tendem a impactar o mercado imobiliário local e isso se mostra um pouco mais latente, a partir da adesão da UFV ao REUNI, pois, a partir desse momento, foram criados diversos novos cursos. Com relação ao quantitativo de vagas e cursos gerados na UFV no período de 2002 - antes da implementação do REUNI - e de 2014 - dois anos após o término do programa, constatam-se a criação de 7 (sete) cursos e a ampliação do número de vagas em 3 (três) cursos distintos ${ }^{6}$. Dessa maneira, de um montante anual de 1.770 vagas (2002), passou para 2.320 vagas (2014), ou seja, 550 novas vagas (um aumento de $30 \%$ ), que, numa projeção de cinco anos, tem-se 2.750 novos estudantes. No entanto, mesmo perante a expressividade do programa REUNI no processo de expansão, acredita-se que, desde a década de 1980, início da pesquisa, até a década de 2010, houve uma provável correlação entre a UFV e seus planos de expansão e a produção da cidade, por parte dos agentes imobiliários, sobretudo na zona central.

Esta ideia é corroborada por Maria et al. (2015), ao mencionarem que a atuação do mercado imobiliário em Viçosa tem sido direcionada a partir da demanda crescente gerada pela expansão da UFV, principalmente após a década de 2000.

É possível aferir que a expansão de novos cursos possa ter contribuído de forma considerável para as transformações nos processos de uso e ocupação do solo nas áreas adjacentes ao campus da UFV, sobretudo referente à natureza dos comércios e serviços disponíveis, e nas formas do morar. Destaca-se, também, a partir das discussões de Paula (2013, 2019), o aumento na produção de imóveis, principalmente os verticalizados, e as diferenciações em suas tipologias.

Atualmente, o campus da UFV em Viçosa conta com 45 cursos, 23 programas de pós-graduação (mestrado e doutorado) e um Colégio de Aplicação - COLUNI. A Tabela 1 ilustra os percentuais referentes ao número de alunos e docentes.

Tabela 1 - Perfil, número e categoria dos estudantes e docentes da UFV no ano de 2018

\begin{tabular}{|c|c|c|}
\hline Perfil & Categoria & Número \\
\hline \multirow{4}{*}{ Estudantes } & Ensino Médio & 821 \\
\hline & Graduação & 11.367 \\
\hline & Pós-Graduação (Stricto Senso) & 2.853 \\
\hline & Pós-Graduação (Lato Sensu) & 528 \\
\hline \multirow{7}{*}{ Docentes } & Total & 15569 \\
\hline & Pós Doutor & 27 \\
\hline & Doutor & 821 \\
\hline & Mestre & 122 \\
\hline & Especialista & 26 \\
\hline & Graduados & 22 \\
\hline & Total & 1018 \\
\hline
\end{tabular}

Fonte: UFV em números (UFV, 2018). Elaborada pela autora (2019).

A partir dos dados apresentados na Tabela 1, é possível observar, de forma quantitativa, os percentuais numéricos referentes ao número de alunos e professores da instituição, e notar a

\footnotetext{
${ }^{5}$ Acredita-se que haja outros fatores mais que possam ter contribuído para a transformação da cidade, fatores estes de escala global, nacional ou local, econômicos e/ou políticos; entretanto, esta pesquisa se atém, essencialmente, ao papel exercido pela universidade.

6 Dentre os cursos criados, mencionam-se: Ciências Sociais, Enfermagem, Medicina, Licenciaturas em Ciências Biológicas, Física, Matemática e Química; e ampliação de vagas nos cursos de Educação Infantil, Secretariado Executivo Trilíngue e Zootecnia.
} 
expressividade quanto ao número de alunos, que corresponde a aproximadamente um quinto da população do município.

No que tange à tipologia do campus da UFV, partindo-se da análise de Sanfeliu (2011), é possível classificá-la como um modelo de campus concentrado, pois, mesmo concentrando suas instalações em um único espaço, possui melhor interação com o tecido urbano, devido à proximidade, mas apresenta um grande impacto territorial, muitas vezes, de caráter dominante na área em que se localiza. Essa tipologia é reforçada a partir de comentários na cidade, tais como "até as quatro pilastras tem-se uma cidade, após as quatro pilastras, outra cidade". Tais comentários se referem à divisão entre a cidade e o campus, expressa não somente por um elemento físico, as quatro pilastras, mas também de forma simbólica, assim como as diferenças estruturais dos locais.

Próximo às quatro pilastras (Figura 1), tem-se uma das principais vias de acesso ao campus, a Avenida P.H. Rolfs, concentrando muitos equipamentos comerciais e residenciais, na figura de salas comerciais e apartamentos. 0 crescimento de estabelecimentos comerciais nesta avenida cresceu de forma substancial nos últimos anos e a hipótese colocada pelo trabalho é de que o aumento e a diversidade dos equipamentos tenham uma possível correlação com o aumento do público estudantil e de professores ${ }^{7}$. Trata-se de uma diversidade de equipamentos comerciais, dentre os quais sorveterias, padarias, farmácias, restaurantes, lanchonetes, principalmente fast foods, copiadoras, boutiques, salões de beleza e outros. A presença de franquias, tais como Chilli Beans, Bob's, Carmen Steffens, O Boticário, evidencia mudanças no padrão dessas áreas, podendo revelar um processo de enobrecimento da área. A morfologia e a diversidade presentes nesta avenida se diferem, de forma substancial, do restante da zona central da cidade, concentrando os equipamentos comerciais mais sofisticados da cidade ${ }^{8}$.

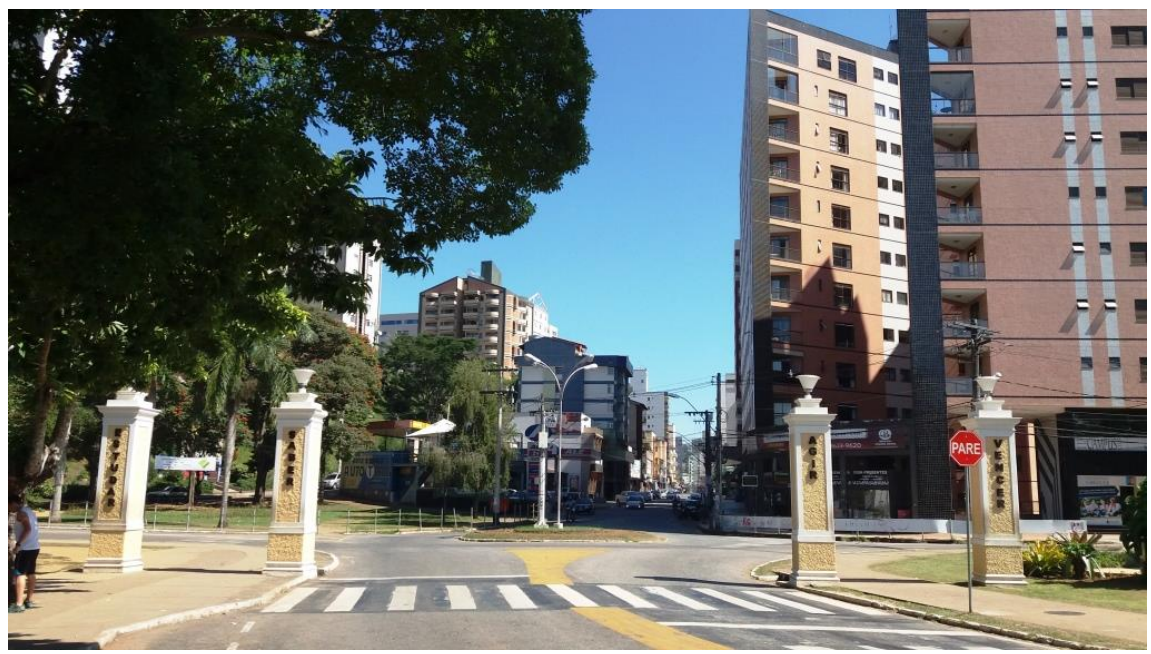

Figura 1 - Localização das Quatro Pilastras e, ao fundo, a Av. PH Rolfs. Fonte: Stephan (2016).

Outras vias próximas à UFV também passaram por transformações substanciais nos últimos anos, principalmente a partir dos anos 2000, conforme atestam os dados de alvarás de construções analisados. Uma delas seria a Rua Vereador José Valentim da Cruz (Ladeira dos Operários), na qual foi construído um conjunto de edifícios com apartamentos de 1 (um), 2 (dois) e 3 (três) quartos, em local com vista

\footnotetext{
${ }^{7}$ A chegada de novos equipamentos comerciais, assim como o enobrecimento desta via, coincide com o período de expansão da instituição promovido pelo REUNI.

8 Processos de reconfiguração urbana, acarretando enobrecimento de certas áreas nas cidades, podem revelar mudanças no padrão de consumo da população, obviamente, mas, no caso de Viçosa, a via escolhida para a materialização desse processo "coincidentemente" seria também uma das principais vias de acesso ao campus e que abriga um fluxo intenso de estudantes e professores diariamente, via mobilidade urbana.
} 
privilegiada para o campus da UFV. A rua de acesso ao conjunto foi fechada com autorização da prefeitura, com instalação de portão e guarita ${ }^{9}$ (Figura 2).

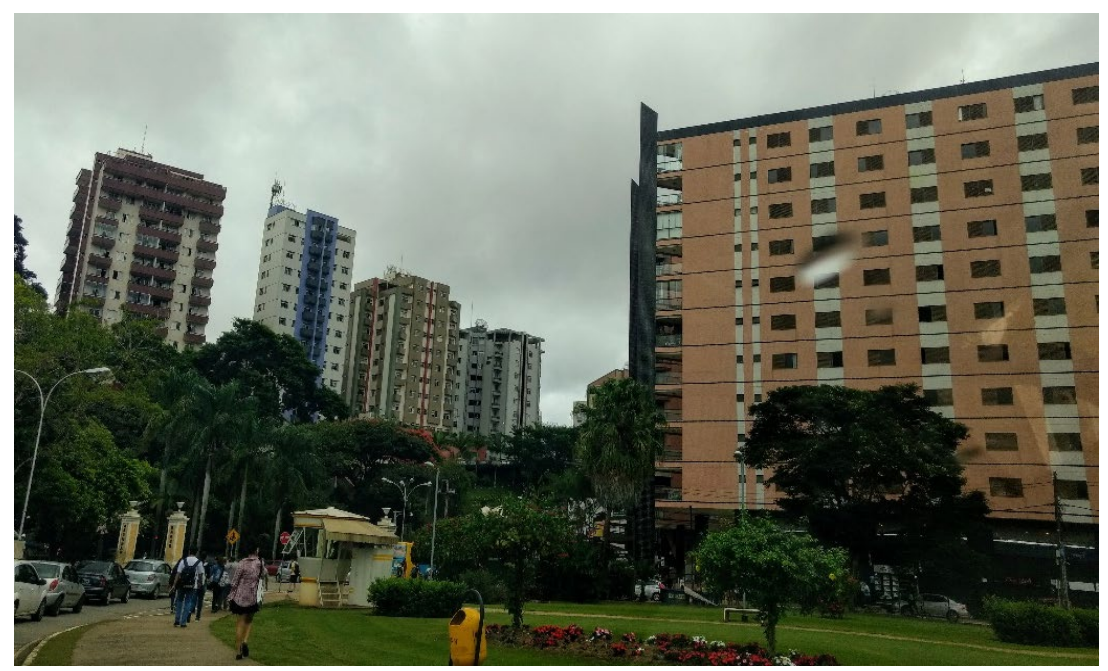

Figura 2 - Conjunto de edifícios na forma de condomínio. Fonte: Paula (2019).

Outra via de destaque seria a Rua dos Estudantes, que se encontra totalmente verticalizada, não havendo mais nenhuma residência unifamiliar. A grande maioria, senão a sua totalidade, de habitações verticais, são construídas com o intuito de atender ao público estudantili10, que, conforme já destacado anteriormente, chega a ser de até 16.000 estudantes, sendo, a maior parte, oriunda de outras cidades.

No que se refere ao uso e ocupação do espaço, a verticalização observada na cidade, principalmente na zona central, tem chamado a atenção de várias pesquisas, por ser algo sui generis para uma cidade de características interioranas. Acredita-se que o incremento para este fenômeno seria dado pela UFV e pelo público que ela recebe diariamente, sejam novos professores e/ou estudantes, mas, principalmente, os estudantes, público mirado pelos promotores imobiliários e, acima de tudo, pelos investidores, agentes em potencial identificados no trabalho de Paula (2019).

A verticalização na zona central da cidade se apresenta como um processo desde a década de 1980 , se mostrando um pouco mais efetivo na década de 1990, mas alcançando um boom imobiliário a partir dos anos 2000. Diversos terrenos passaram a abrigar edifícios multifamiliares e habitações unifamiliares foram demolidas para dar lugar a novos edifícios. No período compreendido entre 1980 e 2012, foram construídos cerca de 100 novos edifícios multifamiliares, com quatro ou mais pavimentos.

A partir dos dados apresentados por Paula (2019), os anos 2000 foram marcados por uma produção intensa de edifícios, principalmente de apartamentos de um e dois quartos, com o objetivo de atender a uma demanda específica: os estudantes. Primeiramente, houve uma produção voltada para dois quartos, seguida da produção voltada para um quarto. Esta produção intensa de apartamento de 1 e 2 quartos coincide com a adesão da UFV ao programa REUNI, mencionado anteriormente. Conforme atestado anteriormente, houve um incremento de 550 pessoas, num curto espaço de tempo, quase todas moradoras de outras cidades, que, ao se mudaram para Viçosa, demandaram habitação, serviços, infraestruturas etc. Em uma projeção de cinco anos, haveria incremento de 2.750 novos estudantes.

Entre os cursos criados, merece destaque, pela expectativa que criou no mercado imobiliário, o curso de Medicina. 0 curso foi criado em setembro de 2007, mas teve início apenas em 2009. Apesar de estas expansões terem se dado por volta de 2007, a notícia sobre elas é anterior. Assim, o ano de 2006 reflete

\footnotetext{
${ }^{9}$ Este conjunto de prédios foi construído anteriormente ao REUNI, mas já evidencia uma possível influência da UFV sobre o uso dos espaços, tendo em vista que a grande maioria residente nos edifícios é caracterizada por estudantes e/ou professores.

${ }^{10}$ Não foi possível aferir, em dados quantitativos, o estoque de imóveis ocupados pelos estudantes, pois o acesso a esta informação foi dificultado pelo não acesso a um cadastro de perfil do locatário e comprador por parte das imobiliárias. As impressões foram registradas a partir da fala dos corretores, que foram categóricos ao afirmar que o grande estoque comercializado por eles, seja locação ou venda, tem como finalidade atender aos estudantes, em primeiro lugar, e aos professores universitários, em segundo.
} 
a antecipação dos promotores imobiliários à nova demanda que estava por se instalar na cidade, ao serem entregues, naquele ano, sete novos empreendimentos verticais residenciais, conforme pôde ser constatado por Paula (2019).

É importante destacar que a criação desses cursos deu origem a uma expectativa e uma dinamização do mercado de imóveis, principalmente, o curso de Medicina. No entanto, referente à expectativa colocada pela abertura do curso de Medicina, para os corretores, esta se mostrou ilusória, dado que o número de vagas abertas anualmente (50) era muito menor do que projetavam. Coincide também com a criação do curso de Medicina, a vinda de algumas das franquias mencionadas anteriormente.

Diante da expressividade da figura do estudante, vale destacar que a forma de morar dos mesmos tende a variar de acordo com a sua renda, e isso, claramente, é observado pelos promotores imobiliários e investidores. Os de renda mais baixa procuram morar nos alojamentos oferecidos pela UFV, no entanto a demanda é muito maior que a oferta de vagas. Assim, outra forma de moradia estudantil mais barata são as "repúblicas" e os quartos alugados de famílias, categorias predominantes nas décadas de 1980 e 1990, na cidade. Várias casas eram alugadas para esta finalidade, além de alguns apartamentos, porém de tipologias maiores, com três a quatro quartos.

No entanto, a partir dos anos 2000, nota-se uma preferência, por parte do estudante, por moradias individuais, caracterizadas não mais por casas (habitação unifamiliar), mas por apartamentos, principalmente de dimensões reduzidas, com um quarto ${ }^{11}$. Mas, independentemente da escolha da tipologia habitacional, uma característica se mostra comum à grande maioria dos estudantes, a preferência por imóveis localizados nas proximidades da UFV, sobretudo na zona central e, em menor escala, em bairros limítrofes.

Os estudantes passam a ser vistos como uma demanda em potencial pelos promotores imobiliários, acima dos professores universitários, dado seu percentual quantitativo. Para eles, são projetadas e criadas tipologias habitacionais distintas, resgatando, até mesmo, tipologias "exclusivas" de grandes metrópoles. Dentre estas tipologias, menciona-se a figura dos flats e lofts, que vêm crescendo na cidade, principalmente na zona central, após a década de 2000. Trata-se de apartamentos estilo quarto/sala, mas trazem consigo uma conotação de "modernidade", um estilo de vida de grandes cidades e metrópoles. Os prédios que abrigam os flats, normalmente, possuem determinados serviços, tais como lavanderia, padaria, academia, mercado, enfim (Paula, 2019).

Os flats têm sido vendidos já mobiliados, tratando-se de uma estratégia dos promotores imobiliários e investidores, pois acredita-se que o imóvel, ao ser apresentado ao cliente já mobiliado, mostra-se mais atraente. Inicialmente, foram observados uma movimentação e um interesse por parte dos investidores por esses novos tipos de imóveis (lofts e flats); no entanto, pelo fato de serem uma "novidade" na cidade, ainda não é possível mensurar seu impacto no mercado e se tem atraído grande parcela de investidores e consumidores, como os estudantes.

As transformações, no tocante ao uso e ocupação do solo na zona central, estão atreladas ao papel dos agentes na produção deste mesmo espaço, tendo destaque, neste trabalho em particular, os promotores imobiliários. Tal agente passou por transformações, sobretudo, em sua caracterização. 0 perfil do promotor imobiliário na década de 1980 era caracterizado, quase que exclusivamente, pela figura do construtor imobiliário, o qual, de forma um pouco precária, atendia às suas próprias demandas de incorporação, podendo até mesmo exercer a função de corretor ${ }^{12}$. Já no final da década de 1990, observase uma nova divisão do trabalho, semelhante às organizações de cidades de maior porte, com o surgimento do incorporador imobiliário, exclusivamente. Com relação às mudanças no perfil dos promotores imobiliários atuantes na zona central, na década de 2000, as empresas começaram a aparecer

\footnotetext{
${ }^{11}$ Há de se destacar que, o trabalho não objetivou estudar as razões objetivas e subjetivas que levaram ao desejo por uma moradia individualizada, mas apenas levantando e problematizando a possível correlação entre a figura dos estudantes e os promotores imobiliários e investidores.

12 De acordo com os dados levantados, em 1980, havia poucas empresas atuantes no setor da construção civil, somando-se apenas quatro empresas. Todos os outros empreendimentos foram construídos por pessoas físicas.
} 
em número maior na cidade e muitas delas unificaram os serviços de incorporação, construção e agente comercial numa mesma empresa, ficando responsável pela venda e negociação direta de seus imóveis.

Mas é importante destacar também outra figura importante para a intensificação da produção de imóveis e diversificação dos serviços na cidade, a figura do investidor, elemento este decisivo para tais transformações (Paula, 2019). Os promotores imobiliários notaram que, além da demanda em potencial (estudantes), havia investidores interessados em adquirir as novas edificações construídas, sendo que tal fato foi significativo para alavancar a produção de imóveis, pois, como alega Baltrusis (2006, p. 126), "[...] se o mercado produz é porque existe alguém disposto a consumir aquele produto". 0 surgimento do investidor foi então essencial para esse processo, pois adquiriam o imóvel com o objetivo de locação ou revenda. Este novo agente, os investidores, se reafirma no mercado imobiliário da cidade, principalmente após a década de 2000.

Na década de 1990, nota-se a presença de alguns investidores na cidade, mas eram caracterizados por agentes locais; mas, é a partir dos anos 2000, que a figura do investidor se torna mais proeminente, sobretudo na zona central. Tais investidores, caracterizados agora não somente agentes locais, mas também externos - oriundos de cidades vizinhas -, formaram um novo segmento imobiliário na cidade e foram atraídos pelo boom imobiliário vivenciado na zona central. Os investidores também vislumbravam a presença da UFV como um elemento capaz de gerar lucro e renda.

As empresas construtoras constataram que havia uma aceitação de novas tipologias de imóvel por parte do estudante, mas também por parte do investidor, surgindo, assim, vários construtores adotando o mesmo procedimento, pois se fazia e se vendia rapidamente. Neste contexto, tem-se um público pagante (estudante) e um público investidor. Um não existe sem o outro.

Neste contexto, pessoas da região que tinham um retorno de aluguel fraco em suas cidades passaram a investir em Viçosa ${ }^{13}$. Mas sempre com a preferência pela zona central, pois sabiam do retorno, dada a proximidade com a Universidade. Muitos dos investidores foram formados por agricultores, profissionais liberais e comerciantes.

Destaca-se, dessa forma, que a dinâmica do mercado imobiliário não é produzida apenas pelos agentes econômicos (construtores, incorporadores), mas também pelos agentes compradores/consumidores, de forma direta ou indireta, alavancando o surgimento de estratégias de venda/consumo (Ramires, 1998). 0 consumidor passa a ser também agente produtor na dinâmica do mercado imobiliário.

De acordo com Fix (2007), na relação entre os promotores imobiliários e os investidores, é travado um conflito, em que a maior parte dos promotores imobiliários se mostra preocupada com os empreendimentos até a comercialização; logo, há um interesse na criação de novas localizações e centralidades, diferentemente dos investidores, que necessitam que as centralidades atuais permaneçam valorizadas.

O fato de que a construção civil estava aquecida na cidade e havia uma demanda em potencial por apartamentos menores - a qual foi percebida não somente pelos investidores, mas, também, e primeiramente, pelos construtores - fez com que, conforme os êxitos desse mercado fossem alcançados, novos investimentos e novas construções fossem materializados.

Dessa forma, é possível observar uma "convenção urbana", que, para Abramo (2007b, p. 125), pode ser formada...

[...] a partir do momento em que a maioria dos participantes do mercado faz-se de imitadora, é possível imaginar um processo de convergência das antecipações em torno de uma conviç̧ão qualquer [...] o papel dos comportamentos imitativos será, pois, determinante para o surgimento da convenção.

A convenção urbana seria formada, então, a partir de uma opinião convencional e compartilhada pelos atores urbanos sobre a escolha e a localização de determinados edifícios, assim como a localização residencial de determinados tipos de famílias (Abramo, 2007b).

\footnotetext{
${ }^{13}$ Estes investidores adquiriam os imóveis, sejam em planta ou já construídos, e destinavam os mesmos para locação, principalmente para estudantes, segundo relatos das imobiliárias da cidade.
} 
No entanto, o que deveria se mostrar como uma "diferenciação do estoque imobiliário" acaba por desencadear uma "homogeneização do estoque imobiliário". Neste contexto, Abramo (2007a) alerta para o fato de que, a partir do momento em que há uma homogeneização do estoque de imóveis, os promotores imobiliários se veem obrigados a introduzir novos produtos no mercado, na tentativa de se manterem no mesmo. E é o que vem acontecendo na zona central de Viçosa, com a inserção de imóveis de três e quatro quartos, imóveis comerciais, lofts e flats, na tentativa de diversificar o público alvo, principalmente para os professores universitários, com o lançamento de imóveis maiores, de três e quatro quartos (Paula, 2019).

As mudanças na tipologia dos apartamentos construídos se deram em função da saturação da oferta de imóveis de um e dois quartos, e, consequentemente, causaram a queda no número de investidores, se mostrando assim um processo de desaceleração. É relevante considerar também o contexto econômico vivenciado por diversos setores no país, ocasionando uma retração no mercado, de uma maneira geral. A queda na produção de edifícios pode estar atrelada ao cenário econômico brasileiro, mas é notável que a produção dos imóveis que ocorreu ao longo dos anos centralizou-se em uma demanda potencial. Afinal, caso não houvesse esta demanda - estudantes -, o mercado se portaria da mesma forma?

Neste sentido, diante dos dados coletados e observados, é possível mensurar que, como alega Vainer (2000), a cidade, particularmente a zona central de Viçosa, passa a ser vista como uma empresa, por parte dos promotores imobiliários e investidores, constituindo-se como um fixo norteador dos investimentos, a UFV. A partir do momento em que a cidade passa a ser concebida como um agente econômico, ela tende a atuar no contexto de um mercado, encontrando, neste, a regra e o modelo do planejamento e execução de suas ações. De uma forma geral, ainda segundo Vainer (2000, p. 86), o

[...] agir estrategicamente, agir empresarialmente significa, antes de mais nada, ter como horizonte o mercado, tomar decisões a partir das informações e expectativas geradas no e pelo mercado.

\section{Considerações finais}

Tendo em vista a proximidade entre o campus da UFV e a zona central, essa área tende a sofrer o impacto direto dos planos de expansão da Universidade, como pode constatar este trabalho. A expansão da UFV, traduzida no aumento do número de cursos de graduação e pós-graduação, e, consequentemente, na ampliação do número de vagas, bem como na contratação de novos professores e servidores, gera imediatamente nova demanda por imóveis e serviços comerciais na zona central.

Há uma tendência dessa nova população, que se muda para Viçosa, de procurar local próximo à Universidade para morar, fato que gera uma expectativa e movimentação no mercado imobiliário, e, ao mesmo tempo, contribui para a valorização da área. A alta demanda e a oferta limitada de lotes na zona central têm inflacionado esse mercado, o que faz com que os promotores imobiliários busquem tirar o máximo proveito desses lotes.

Dessa forma, observa-se a prevalência dos interesses do capital imobiliário, primeiramente, na definição tanto do modo de morar na zona central da cidade quanto do perfil dos moradores, visto que nem todos têm renda suficiente para pagar por um imóvel na zona central. No que diz respeito ao modo de morar, o setor imobiliário implanta na cidade um padrão de moradia, que até então era típico apenas das médias e grandes cidades, na tentativa de atender, principalmente, ao público estudantil, que fixa uma residência temporária na cidade para estudar na UFV. A oferta de moradias tem se restringido a apartamentos e, mesmo assim, com tipologias limitadas a apartamentos de quarto e sala, quitinetes, flats e lofts, em que o usuário tem pouca ou nenhuma condição de escolha, visto que, de um modo geral, o programa de necessidades é subdimensionado, as dimensões dos apartamentos atendem apenas ao mínimo exigido pela legislação e são vendidos mobiliados.

Outra constatação importante foi a transformação no papel e caracterização do promotor imobiliário na cidade, sendo os anos 2000 marcados por um perfil extremamente mais qualificado, formado por empresas, sendo muitas delas com uma divisão mais especializada de trabalho. Somada às 
transformações no perfil dos promotores, destaca-se a figura do investidor como um agente essencial na dinamização imobiliária da zona central.

Neste sentido, este trabalho, além de fazer uma análise da interiorização de novos campus das IFES em cidades pequenas e médias, e dos seus impactos diretos no processo de uso e ocupação do espaço urbano, alude também para a importância de estudar e dimensionar estes impactos nestas mesmas cidades, na medida em que, muitas delas não possuem, de imediato, uma infraestrutura adequada para atender à nova demanda que se instala na cidade, e muito menos praticam políticas eficientes de controle do ordenamento territorial. Cabe, assim, uma discussão referente à capacidade e/ou incapacidade do município, que vai receber novos campi universitários, de abarcar grandes impactos.

\section{Referências}

Abramo, P. (2007a). A cidade com-fusa: a mão inoxidável do mercado e a produção da estrutura urbana nas grandes metrópoles latino americanas. Revista Brasileira de Estudos Urbanos e Regionais, 9(2), 25-54.

http://dx.doi.org/10.22296/2317-1529.2007v9n2p25.

Abramo, P. (2007b). A cidade caleidoscópica: coordenação espacial e convenção urbana: uma perspectiva heterodoxa para a economia urbana. Rio de Janeiro: Bertrand Brasil.

Amorim, C. C. (2010). O uso do território brasileiro e as instituições de ensino superior (Tese de doutorado). Faculdade de Filosofia, Letras e Ciências Humanas, Universidade de São Paulo.

Baltrusis, N. (2006). A valorização fundiária da propriedade urbana. Cadernos Metrópole, (16), 121-139.

Baumgartner, W. H. (2015a). Cidades universitárias, cidades medias, cidades pequenas: analises sobre o processo de instalação de novos campi universitários. Espacio Abierto, 5(1), 73-93.

http://dx.doi.org/10.36403/espacoaberto.2015.2525.

Baumgartner, W. H. (2015b). Universidades públicas como agentes de desenvolvimento urbano e regional de cidades médias e pequenas: uma discussão teórica, metodológica e empírica. Revista GeoTextos, 11(1), 91-111. http://dx.doi.org/10.9771/1984-5537geo.v11i1.12013.

Correa, R. L. (2000). O espaço urbano (4. ed.). São Paulo: Ática.

Correa, R. L. (2011). Sobre agentes sociais, escala e produção do espaço: um texto para discussão. In A. F. A. Carlos, M. L. Souza, \& M. E. B. Sposito (Eds.), A produção do espaço urbano: agentes e processos, escalas e desafios (pp. 4351). São Paulo: Contexto.

Fix, M. (2007). Alianças estratégicas na produção do espaço urbano. In M. Fix (Ed.), São Paulo cidade global: fundamentos financeiros de uma miragem (pp. 113-137). São Paulo: ANPUR, Boitempo.

Magalhães, L. C. (2014). $O$ campus universitário como equipamento singular do meio urbano: ensaio em Três Rios, Brasil (Dissertação de mestrado). Faculdade de Ciência e Tecnologia, Universidade Fernando Pessoa, Porto.

Maria, A. C. S., Faria, T. C. A., \& Stephan, I. I. C. (2015). Um retrato da evolução urbana de Viçosa-MG: impactos da federalização da UFV sobre a cidade (1969-2014). Revista Brasileira de Planejamento e Desenvolvimento, 3(1), 37 54. http://dx.doi.org/10.3895/rbpd.v3n1.3572.

Paula, K. A. (2013). A produção do espaço urbano vertical na zona central de Viçosa - MG, no período de 1980-2012 (Dissertação de mestrado). Faculdade de Arquitetura e Urbanismo, Universidade Federal de Viçosa, Viçosa.

Paula, K. A. (2019). 0 processo de verticalização na zona central da cidade de Viçosa-MG: uma análise a partir da expansão da Universidade Federal de Viçosa e do seu impacto na estruturação do espaço urbano. GeoTextos, 15(1), 65-87. http://dx.doi.org/10.9771/geo.v15i1.30473.

Pinheiro, C. H. L. (2018). Cidade, universidade e percepções docentes no contexto da expansão interiorizada do ensino superior público no Estado do Ceará. Revista INTERthesis, 15(2), 38-54. http://dx.doi.org/10.5007/18071384.2018v15n2p38. 
Ramires, J. C. L. (1998). A verticalização do espaço urbano de Uberlândia: uma análise da produção e consumo da habitação (Tese de doutorado). Universidade de São Paulo, São Paulo.

Sánchez, F. (2010). A cidade-mercadoria: produção do espaço e a lógica cultural nos processos de renovação urbana. In F. Sanchez (Ed.), A reinvenção das cidades para um mercado mundial (pp. 41-135). Chapecó: Argos.

Sanfeliu, C. B. (2011). La inserción de la Universidad en la estructura y forma urbana: el caso de la Universitat de Lleida. Revista Electrónica de Geografía y Ciencias Sociales, 15(381).

Sayegh, L. M. L. (2009). A dinâmica urbana em Ouro Preto: conflitos decorrentes de sua patrimonialização e de sua consolidação como cidade universitária (Dissertação de mestrado). Faculdade de Arquitetura e Urbanismo, Universidade Federal da Bahia, Salvador.

Stephan, I. (2016). Por amor as cidades. Recuperado em 12 de abril de 2019, de https://italostephanarquiteto.blogspot.com/2016/04/lindo-campus.html

Universidade de Viçosa - UFV. Pro-Reitoria de Planejamento e Orçamento. (2018). UFV em números. Viçosa.

Vainer, C. (2000). Pátria, empresa e mercadoria. In O. Arantes, C. Vainer, \& E. Maricato (Eds.), A cidade do pensamento único: desmanchando consensos (pp. 75-103). Petrópolis: Vozes.

Weska, A. R., Silva, A. S., Lliescu, D., Nascimento, H. M. N., Martins, J. L., Neder, M. L. C., Silva, T. N., \& Rodrigues, Y. P. (2012). Análise sobre a expansão das Universidades Federais 2003 a 2012: relatório da Comissão Constituída pela Portaria no 126/2012. Brasília: Ministério da Educação.

Editor: Rodrigo Firmino

Recebido: Abr. 26, 2019

Aprovado: Out. 28, 2019 